\title{
Jiangella muralis sp. nov., from an indoor environment
}

\author{
Correspondence \\ P. Kämpfer \\ peter.kaempfer@umwelt.uni- \\ giessen.de
}

\author{
P. Kämpfer, ${ }^{1}$ J. Schäfer, ${ }^{1}$ N. Lodders ${ }^{1}$ and K. Martin ${ }^{2}$ \\ ${ }^{1}$ Institut für Angewandte Mikrobiologie, Justus-Liebig-Universität Giessen, D-35392 Giessen, \\ Germany \\ ${ }^{2}$ Leibniz-Institut für Naturstoff-Forschung und Infektionsbiologie e.V., Hans-Knöll-Institut, \\ D-07745 Jena, Germany
}

The genus Jiangella was described by Song et al. (2005) and harboured at that time a single species, Jiangella gansuensis. Further species, Jiangella alkaliphila and Jiangella alba, were described by Lee (2008) and Qin et al. (2009), respectively. All Jiangella species that have been described so far accommodate aerobic, Gram-positive actinobacteria with LL-2,6-diaminopimelic acid in the cell-wall peptidoglycan and MK-9 $\left(\mathrm{H}_{4}\right)$ as the predominant menaquinone.

Strain $15-\mathrm{Je}-017^{\mathrm{T}}$ was isolated from a cellar wall that was colonized with moulds as described by Kämpfer et al. (2009). Strain $15-\mathrm{Je}-017^{\mathrm{T}}$ was maintained on an organic medium, M79 agar (medium 426; http://www.dsmz.de), and was preserved at $-80{ }^{\circ} \mathrm{C}$ as described previously (Kämpfer et al., 2009).

Colony morphology was determined on M79 agar, nutrient agar (NA; Difco), International Streptomyces Project (ISP) 2 and 3 (Shirling \& Gottlieb, 1966) and GYM agar

Abbreviations: ISP, International Streptomyces Project; pNA, p-nitroanilide; pNP, $p$-nitrophenyl.

The GenBank/EMBL/DDBJ accession number for the 16S rRNA gene sequence of strain $15-\mathrm{Je}-017^{\top}$ is FN645214.

Two supplementary figures are available with the online version of this paper. (medium 65; http://www.dsmz.de). Cell morphology and Gram staining were determined by phase-contrast microscopy (Axioscope; Carl Zeiss Jena) and stereomicroscopy (Stemi 2000; Carl Zeiss Jena). Cells of 5-day-old liquid cultures of strain $15-\mathrm{Je}-017^{\mathrm{T}}$ are small, irregular rods and stain Gram-positive. After transfer to fresh liquid medium or agar slides, rods gave rise to mycelium-like filaments (Supplementary Fig. S1, available in IJSEM Online). Colonies on NA were white and slightly beige with a matt surface and, after 2 weeks, a very short, white aerial mycelium was formed (Supplementary Fig. S2). The same observations were made on M79 and GYM agar, whereas on ISP 2 the formation of aerial mycelium was detected only after 4 weeks of incubation at $28{ }^{\circ} \mathrm{C}$ and on ISP 3 no aerial mycelium was observed.

Isolation of genomic DNA was performed as described by Schäfer et al. (2010). Multiple alignment of 16S rRNA gene sequences and analysis were performed using MEGA version 4 (Tamura et al., 2007). A neighbour-joining tree was created using genetic distances calculated with distance options according to Kimura's two-parameter model (Kimura, 1980) (Fig. 1). Bootstrap values were calculated using 1000 replications. The $16 \mathrm{~S}$ rRNA gene sequence of strain $15-\mathrm{Je}-017^{\mathrm{T}}$ was a continuous stretch of $1363 \mathrm{bp}$. 


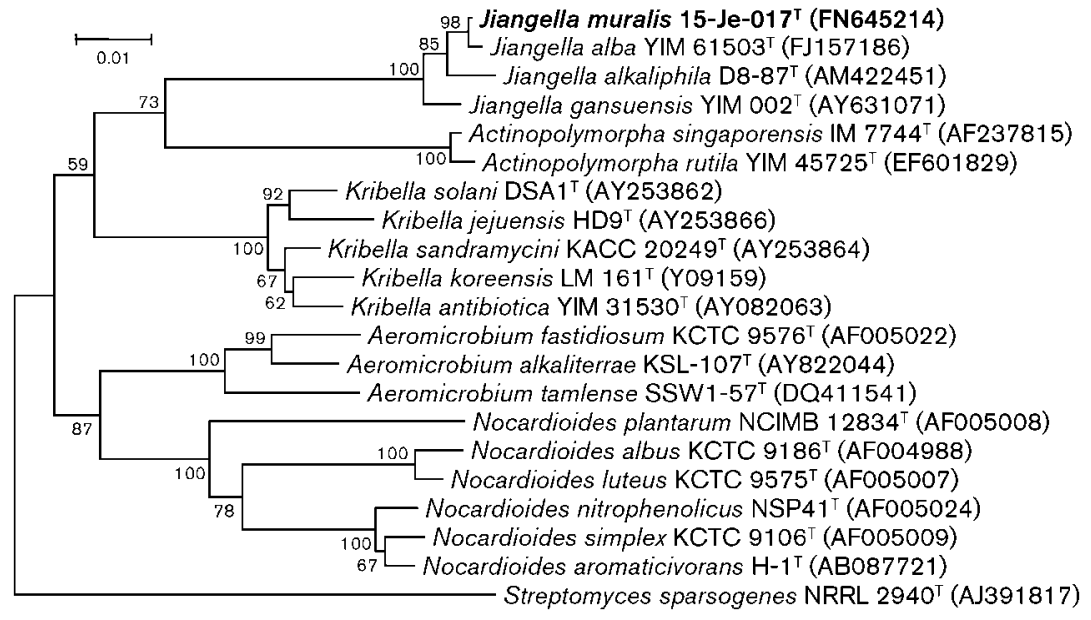

Fig. 1. Phylogenetic analysis based on $16 \mathrm{~S}$ rRNA gene sequences showing relationships between strain $15-\mathrm{Je}-017^{\top}$ and related taxa. Bootstrap values $(>50 \%)$ based on 1000 replications are shown at branch nodes. Bar, 0.01 substitutions per nucleotide position.
Sequence similarity calculations after the neighbour-joining analysis indicated that the closest relatives of strain 15-Je$017^{\mathrm{T}}$ were J. alba YIM $61503^{\mathrm{T}}(99.7 \%$ 16S rRNA gene sequence similarity), J. alkaliphila D8-87 ${ }^{\mathrm{T}}(99.0 \%)$ and $J$. gansuensis YIM $002^{\mathrm{T}}(99.0 \%)$.

For chemotaxonomic investigations, strain $15-\mathrm{Je}-017^{\mathrm{T}}$ was cultivated in liquid M79 shaken at 180 r.p.m. at $28{ }^{\circ} \mathrm{C}$ for $48 \mathrm{~h}$. Cell-wall analysis was performed as described by Groth et al. (1996). Whole-cell hydrolysates were prepared for the detection of the isomer of diaminopimelic acid in the cell wall. The amino acids were analysed by TLC on cellulose plates as described by Schleifer \& Kandler (1972). Predominant whole-cell sugars and the occurrence of mycolic acids were determined by TLC as described by Becker et al. (1965) and Minnikin et al. (1975), respectively. Menaquinones were extracted as described by Collins et al. (1977) and analysed by HPLC (Groth et al., 1996). Polar lipids were extracted by the method of Minnikin et al. (1979) and identified by two-dimensional TLC as described by Collins \& Jones (1980). Fatty acid analysis for strain $15-\mathrm{Je}-017^{\mathrm{T}}$ and the reference strains J. alba DSM $45237^{\mathrm{T}}$, J. alkaliphila DSM $45079^{\mathrm{T}}$ and J. gansuensis DSM $44835^{\mathrm{T}}$ was performed according to Kämpfer \& Kroppenstedt (1996) using cells grown on tryptic soy agar at $30{ }^{\circ} \mathrm{C}$ for $48 \mathrm{~h}$.

The chemotaxonomic characteristics of strain $15-\mathrm{Je}-017^{\mathrm{T}}$ were consistent with the affiliation to the genus Jiangella. Whole-cell hydrolysates contained LL-diaminopimelic acid as the diagnostic diamino acid of the peptidoglycan and the major sugars were glucose and rhamnose (wall chemotype I, sensu Lechevalier \& Lechevalier, 1970). The predominant menaquinone was MK-9 $\left(\mathrm{H}_{4}\right)(90 \%)$; traces of MK-8 (5\%) and MK-7 $\left(\mathrm{H}_{2}\right)(1 \%)$ were also detected. Strain $15-\mathrm{Je}-017^{\mathrm{T}}$ showed a complex phospholipid profile (Fig. 2) that was composed of diphosphatidylglycerol, phosphatidylglycerol, phosphatidylinositol and phosphatidylinositol mannoside, which have been shown for the previously described Jiangella species, and seven unknown phospholipids. Phosphatidylcholine, found in J. alkaliphila, was not detected. Mycolic acids were absent. The fatty acid profile of strain $15-\mathrm{Je}-017^{\mathrm{T}}$ contained anteiso- $\mathrm{C}_{15: 0}(30.8 \%)$, iso- $\mathrm{C}_{16: 0}(12.1 \%)$, iso$\mathrm{C}_{15: 0}(11.5 \%)$, iso- $\mathrm{C}_{14: 0}(7.9 \%)$, anteiso- $\mathrm{C}_{17: 0}(7.8 \%)$ and $\mathrm{C}_{17: 1} \omega 8 c(7.5 \%)$ and other fatty acids in smaller proportions. This profile was very similar to those of the reference strains obtained in this study and was congruent with the fatty acid profiles reported by Song et al. (2005), Qin et al. (2009) and Lee (2008), but some quantitative and qualitative differences were observed (Table 1).

Growth of strain $15-\mathrm{Je}-017^{\mathrm{T}}$ at $4,10,20,25,28,37,40$ and $45{ }^{\circ} \mathrm{C}$ was determined on NA. Comparative physiological characterization of strain $15-\mathrm{Je}-017^{\mathrm{T}}$ and the type strains of species of the genus Jiangella was done under identical conditions using methods described previously (Kämpfer et al., 1991). The results are given in Table 2 and the species

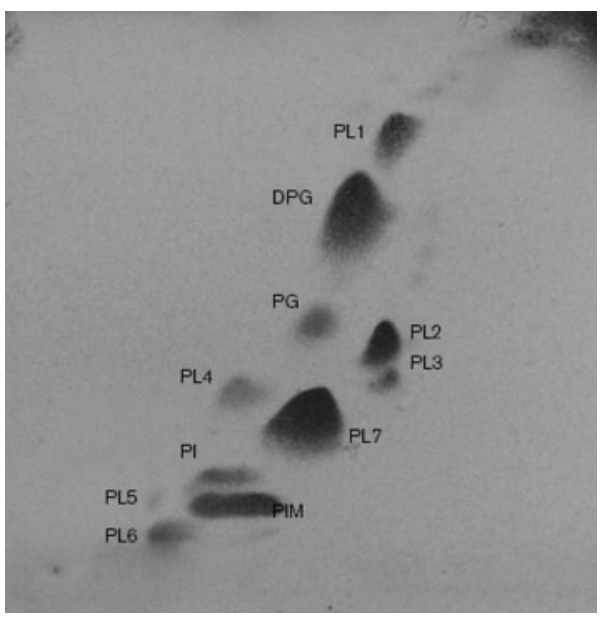

Fig. 2. Two-dimensional TLC of a polar lipid extract from strain $15-J e-017^{\top}$, stained with molybdatophosphoric acid. DPG, Diphosphatidylglycerol; PG, phosphatidylglycerol; PI, phosphatidylinositol; PIM, phosphatidylinositol mannoside, PL1-7, unknown phospholipids. 
Table 1. Major fatty acids of type strains of species of the genus Jiangella

Strains: 1, Jiangella muralis sp. nov. $15-\mathrm{Je}-017^{\mathrm{T}} ; 2$, J. alba DSM $45237^{\mathrm{T}}$; 3, J. alkaliphila DSM $45079^{\mathrm{T}}$; 4, J. gansuensis DSM $44835^{\mathrm{T}}$. Data are percentages of total fatty acids and were obtained in this study.

\begin{tabular}{|c|c|c|c|c|}
\hline Fatty acid & 1 & 2 & 3 & 4 \\
\hline iso- $\mathrm{C}_{14: 0}$ & 7.9 & 4.1 & 9.1 & 2.0 \\
\hline iso- $\mathrm{C}_{15: 1} \mathrm{G}$ & - & - & 1.3 & 2.5 \\
\hline iso- $\mathrm{C}_{14: 0} 3-\mathrm{OH}$ & - & - & 1.4 & - \\
\hline anteiso- $\mathrm{C}_{15: 1} \mathrm{~A}$ & - & - & - & 2.3 \\
\hline iso- $\mathrm{C}_{15: 0}$ & 11.5 & 16.1 & 7.7 & 14.1 \\
\hline anteiso- $\mathrm{C}_{15: 0}$ & 30.8 & 36.8 & 28.4 & 30.4 \\
\hline $\mathrm{C}_{15: 0}$ & 1.7 & - & - & - \\
\hline iso- $\mathrm{C}_{16: 1} \mathrm{G}$ & 1.6 & 1.0 & 4.6 & 3.3 \\
\hline iso- $\mathrm{C}_{16: 0}$ & 12.1 & 10.4 & 22.9 & 6.0 \\
\hline$C_{16: 0}$ & 1.4 & - & - & - \\
\hline iso- $\mathrm{C}_{15: 0} 3-\mathrm{OH}$ & 3.6 & 1.2 & - & 3.7 \\
\hline iso- $\mathrm{C}_{16: 0} 3-\mathrm{OH}$ & - & - & 2.4 & - \\
\hline $\mathrm{C}_{15: 0} 2-\mathrm{OH}$ & 3.8 & 2.0 & 2.7 & 2.5 \\
\hline iso- $\mathrm{C}_{17: 1} \omega 9 c$ & - & 0.9 & - & 2.9 \\
\hline anteiso- $\mathrm{C}_{17: 1} \mathrm{~A}$ & - & 1.1 & 1.0 & 3.5 \\
\hline iso- $\mathrm{C}_{17: 0}$ & 3.1 & 5.8 & 1.9 & 5.6 \\
\hline anteiso- $\mathrm{C}_{17: 0}$ & 7.8 & 14.4 & 11.2 & 13.3 \\
\hline $\mathrm{C}_{17: 1} \omega 8 c$ & 7.5 & 4.3 & 1.2 & 3.7 \\
\hline$C_{17: 0}$ & 4.7 & - & 2.6 & 1.6 \\
\hline $\mathrm{C}_{18: 1} \omega 9 c$ & 1.3 & 0.8 & - & 2.4 \\
\hline $\mathrm{C}_{18: 0}$ & 1.2 & - & - & - \\
\hline iso- $\mathrm{C}_{18: 0}$ & - & - & 1.6 & - \\
\hline
\end{tabular}

description. Only a few tests were able to differentiate strain $15-\mathrm{Je}-017^{\mathrm{T}}$ from the reference strains.

DNA-DNA hybridization experiments were performed between strain $15-\mathrm{Je}-017^{\mathrm{T}}$ and the type strains of species of the genus Jiangella using the method given by Ziemke et al. (1998). Strain $15-\mathrm{Je}-017^{\mathrm{T}}$ showed moderate DNA-DNA relatedness with $J$. alba DSM $45237^{\mathrm{T}}(48.1 \%$; $45.1 \%$ reciprocal hybridization), J. alkaliphila DSM $45079^{\mathrm{T}}$ (27.2, $22.8 \%$ ) and J. gansuensis DSM $44835^{\mathrm{T}}(38.4,32.1 \%)$.

DNA-DNA relatedness and the physiological and chemotaxonomic differences between strain $15-\mathrm{Je}-017^{\mathrm{T}}$ and the type strains of species of the genus Jiangella (Tables 1 and 2) clearly warrant the description of a novel species to accommodate strain $15-\mathrm{Je}-017^{\mathrm{T}}$, for which the name Jiangella muralis sp. nov. is proposed.

\section{Description of Jiangella muralis sp. nov.}

Jiangella muralis [mu.ra'lis. L. fem. adj. muralis pertaining or belonging to a wall(s)].

Forms mycelium-like filaments, about $1.3 \mu \mathrm{m}$ wide. Substrate mycelium on M79 agar is white to beige; aerial mycelium is white. Gram-stain-positive and weakly oxidasepositive. Aerobic respiratory metabolism. Good growth is observed after 3 days on tryptone soy agar, M79 agar and
Table 2. Physiological characteristics of the type strains of species of the genus Jiangella

Strains: 1 , J. muralis sp. nov. $15-\mathrm{Je}-017^{\mathrm{T}}$; 2, J. alba DSM $45237^{\mathrm{T}}$; 3 , J. alkaliphila DSM $45079^{\mathrm{T}} ; 4$, J. gansuensis DSM $44835^{\mathrm{T}}$. Data were obtained in this study. All strains were positive for hydrolysis of aesculin, $p$-nitrophenyl (pNP) phenylphosphonate, 2-deoxythymidine- $5^{\prime}$-pNP phosphate, L-alanine p-nitroanilide (pNA) and L-proline pNA and assimilation of $\mathrm{N}$-acetyl-D-glucosamine, L-arabinose, $p$ arbutin, cellobiose, D-glucose, maltose, D-ribose, sucrose, trehalose, adonitol and pyruvate. All strains were negative for hydrolysis of $o-$ nitrophenyl $\beta$-D-galactopyranoside and L-glutamate- $\gamma$-3-carboxy pNA and assimilation of gluconate, melibiose, D-sorbitol, putrescine, propionate, cis- and trans-aconitate, adipate, 4-aminobutyrate, azelate, citrate, itaconate, mesaconate, suberate, $\beta$-alanine, L-leucine, L-ornithine, L-serine, L-tryptophan, 3-hydroxybenzoate, 4-hydroxybenzoate and phenylacetate. +, Positive; (+), weakly positive; -, negative.

\begin{tabular}{|c|c|c|c|c|}
\hline Characteristic & 1 & 2 & 3 & 4 \\
\hline \multicolumn{5}{|l|}{ Hydrolysis of: } \\
\hline $\mathrm{pNP} \beta$-D-glucuronide & + & + & - & + \\
\hline pNP $\alpha$-D-glucopyranoside & + & - & + & + \\
\hline pNP $\beta$-D-glucopyranoside & - & + & - & + \\
\hline pNP $\beta$-D-xylopyranoside & + & + & - & + \\
\hline bis-pNP phosphate & + & - & - & + \\
\hline pNP phosphorylcholine & + & + & - & + \\
\hline \multicolumn{5}{|l|}{ Assimilation of: } \\
\hline$N$-Acetyl-D-galactosamine & $(+)$ & $(+)$ & - & $(+)$ \\
\hline D-Fructose & $(+)$ & + & - & + \\
\hline D-Galactose & $(+)$ & - & - & $(+)$ \\
\hline D-Mannose & + & + & - & + \\
\hline L-Rhamnose & $(+)$ & - & - & - \\
\hline Salicin & + & + & - & + \\
\hline D-Xylose & $(+)$ & $(+)$ & - & $(+)$ \\
\hline myo-Inositol & - & - & - & $(+)$ \\
\hline Maltitol & + & + & - & $(+)$ \\
\hline D-Mannitol & - & + & $(+)$ & + \\
\hline Acetate & $(+)$ & $(+)$ & - & $(+)$ \\
\hline Fumarate & + & + & - & - \\
\hline Glutarate & - & - & - & $(+)$ \\
\hline DL-3-Hydroxybutyrate & $(+)$ & $(+)$ & - & $(+)$ \\
\hline DL-Lactate & + & $(+)$ & - & + \\
\hline L-Malate & + & $(+)$ & $(+)$ & - \\
\hline Oxoglutarate & $(+)$ & - & - & $(+)$ \\
\hline L-Alanine & $(+)$ & - & - & - \\
\hline L-Aspartate & $(+)$ & - & - & - \\
\hline L-Histidine & $(+)$ & - & - & $(+)$ \\
\hline L-Phenylalanine & $(+)$ & - & - & $(+)$ \\
\hline L-Proline & $(+)$ & - & - & $(+)$ \\
\hline
\end{tabular}

NA at $25-30{ }^{\circ} \mathrm{C}$. Hydrolyses aesculin, p-nitrophenyl (pNP) phenylphosphonate, 2-deoxythymidine- $5^{\prime}$-pNP phosphate, $\mathrm{pNP} \beta$-D-glucuronide, $\mathrm{pNP} \alpha$-D-glucopyranoside, $\mathrm{pNP} \beta$-Dxylopyranoside, bis-pNP phosphate, pNP phosphorylcholine, $\mathrm{L}$-alanine $p$-nitroanilide (pNA) and L-proline pNA. Does not hydrolyse $o$-nitrophenyl $\beta$-galactopyranoside, pNP $\beta$-D-glucopyranoside or L-glutamate- $\gamma$-3-carboxy pNA. As 
sole carbon source, utilizes D-mannose, fumarate, DL-lactate, L-malate, pyruvate, salicin and maltitol, weakly utilizes $\mathrm{N}$ acetyl-D-galactosamine, $\mathrm{N}$-acetyl-D-glucosamine, L-arabinose, $p$-arbutin, cellobiose, D-fructose, D-galactose, Dglucose, maltose, L-rhamnose, D-ribose, sucrose, trehalose, D-xylose, adonitol, D-mannitol, acetate, DL-3-hydroxybutyrate, 2-oxoglutarate, L-alanine, L-aspartate, L-histidine, L-proline and L-phenylalanine, but does not utilize gluconate, melibiose, D-mannitol, myo-inositol, D-sorbitol, putrescine, propionate, cis- or trans-aconitate, adipate, 4aminobutyrate, azelate, citrate, glutarate, itaconate, mesaconate, suberate, $\beta$-alanine, L-leucine, L-ornithine, L-serine, L-tryptophan, 3-hydroxybenzoate, 4-hydroxybenzoate or phenylacetate. The quinone system is composed predominantly of menaquinone MK-9 $\left(\mathrm{H}_{4}\right)$. The polar lipid profile consists of diphosphatidylglycerol, phosphatidylglycerol, phosphatidylinositol, phosphatidylinositol mannoside and seven unknown phospholipids. Major fatty acids $(<5 \%)$ are anteiso- $\mathrm{C}_{15: 0}$, iso- $\mathrm{C}_{16: 0}$, iso- $\mathrm{C}_{15: 0}$, iso- $\mathrm{C}_{17: 0}$, anteiso- $\mathrm{C}_{17: 0}$ and $\mathrm{C}_{17: 1} \omega 8 c$; other fatty acids are present in smaller proportions.

The type strain, $15-\mathrm{Je}-017^{\mathrm{T}} \quad\left(=\mathrm{DSM} \quad 45357^{\mathrm{T}}=\mathrm{CCM}\right.$ $\left.7680^{\mathrm{T}}\right)$, was isolated in Jena, Germany, from a mouldy cellar wall of a house.

\section{Acknowledgements}

We are grateful to Carmen Schult and Gundula Will for excellent technical assistance and Dr Jean Euzéby for support with the nomenclature. The study was supported in part by the Federal Environment Agency (Umweltbundesamt) (grant number FKZ 20562236).

\section{References}

Becker, B., Lechevalier, M. P. \& Lechevalier, H. A. (1965). Chemical composition of cell-wall preparations from strains of various formgenera of aerobic actinomycetes. Appl Microbiol 13, 236-243.

Collins, M. D. \& Jones, D. (1980). Lipids in the classification and identification of coryneform bacteria containing peptidoglycans based on 2,4-diaminobutyric acid. J Appl Bacteriol 48, 459-470.

Collins, M. D., Pirouz, T., Goodfellow, M. \& Minnikin, D. E. (1977). Distribution of menaquinones in actinomycetes and corynebacteria. J Gen Microbiol 100, 221-230.

Groth, I., Schumann, P., Weiss, N., Martin, K. \& Rainey, F. A. (1996). Agrococcus jenensis gen. nov., sp. nov., a new genus of actinomycetes with diaminobutyric acid in the cell wall. Int J Syst Bacteriol 46, 234239.

Kämpfer, P. \& Kroppenstedt, R. M. (1996). Numerical analysis of fatty acid patterns of coryneform bacteria and related taxa. Can $J$ Microbiol 42, 989-1005.

Kämpfer, P., Steiof, M. \& Dott, W. (1991). Microbiological characterization of a fuel-oil contaminated site including numerical identification of heterotrophic water and soil bacteria. Microb Ecol 21, 227-251.

Kämpfer, P., Martin, K., Schäfer, J. \& Schumann, P. (2009). Kytococcus aerolatus sp. nov., isolated from indoor air in a room colonized with moulds. Syst Appl Microbiol 32, 301-305.

Kimura, M. (1980). A simple method for estimating evolutionary rates of base substitutions through comparative studies of nucleotide sequences. J Mol Evol 16, 111-120.

Lechevalier, M. P. \& Lechevalier, H. A. (1970). Chemical composition as a criterion in the classification of aerobic actinomycetes. Int J Syst Bacteriol 20, 435-443.

Lee, S.-D. (2008). Jiangella alkaliphila sp. nov., an actinobacterium isolated from a cave. Int J Syst Evol Microbiol 58, 1176-1179.

Minnikin, D. E., Alshamaony, L. \& Goodfellow, M. (1975). Differentiation of Mycobacterium, Nocardia, and related taxa by thin-layer chromatographic analysis of whole-organism methanolysates. J Gen Microbiol 88, 200-204.

Minnikin, D. E., Collins, M. D. \& Goodfellow, M. (1979). Fatty acid and polar lipid composition in the classification of Cellulomonas, Oerskovia and related taxa. J Appl Microbiol 47, 87-95.

Qin, S., Zhao, G.-Z., Li, J., Zhu, W.-Y., Xu, L.-H. \& Li, W.-J. (2009). Jiangella alba sp. nov., an endophytic actinomycete isolated from the stem of Maytenus austroyunnanensis. Int J Syst Evol Microbiol 59, 2162-2165.

Schäfer, J., Martin, K. \& Kämpfer, P. (2010). Citricoccus parietis sp. nov., isolated from a mould-colonized wall, and emended description of Citricoccus alkalitolerans. Int J Syst Evol Microbiol 60, 271-274.

Schleifer, K. H. \& Kandler, O. (1972). Peptidoglycan types of bacterial cell walls and their taxonomic implications. Bacteriol Rev 36, 407477.

Shirling, E. B. \& Gottlieb, D. (1966). Methods for characterization of Streptomyces species. Int J Syst Bacteriol 16, 313-340.

Song, L., Li, W.-J., Wang, Q.-L., Chen, G.-Z., Zhang, Y.-S. \& Xu, L.-H. (2005). Jiangella gansuensis gen. nov., sp. nov., a novel actinomycete from a desert soil in north-west China. Int J Syst Evol Microbiol 55, 881-884.

Tamura, K., Dudley, J., Nei, M. \& Kumar, S. (2007). MEGA4: molecular evolutionary genetics analysis (MEGA) software version 4.0. Mol Biol Evol 24, 1596-1599.

Ziemke, F., Höfle, M. G., Lalucat, J. \& Rosselló-Mora, R. (1998). Reclassification of Shewanella putrefaciens Owen's genomic group II as Shewanella baltica sp. nov. Int J Syst Bacteriol 48, 179-186. 